\title{
Abrupt warming of the Red Sea
}

\author{
D. E. Raitsos, ${ }^{1}$ I. Hoteit, ${ }^{1}$ P. K. Prihartato, ${ }^{1}$ T. Chronis, ${ }^{2}$ G. Triantafyllou, ${ }^{2}$ \\ and Y. Abualnaja ${ }^{1}$
}

Received 30 April 2011; revised 5 June 2011; accepted 8 June 2011; published 19 July 2011.

[1] Coral reef ecosystems, often referred to as "marine rainforests," concentrate the most diverse life in the oceans. Red Sea reef dwellers are adapted in a very warm environment, fact that makes them vulnerable to further and rapid warming. The detection and understanding of abrupt temperature changes is an important task, as ecosystems have more chances to adapt in a slowly rather than in a rapid changing environment. Using satellite derived sea surface and ground based air temperatures, it is shown that the Red Sea is going through an intense warming initiated in the mid-90s, with evidence for an abrupt increase after $1994\left(0.7^{\circ} \mathrm{C}\right.$ difference pre and post the shift). The air temperature is found to be a key parameter that influences the Red Sea marine temperature. The comparisons with Northern Hemisphere temperatures revealed that the observed warming is part of global climate change trends. The hitherto results also raise additional questions regarding other broader climatic impacts over the area. Citation: Raitsos, D. E., I. Hoteit, P. K. Prihartato, T. Chronis, G. Triantafyllou, and Y. Abualnaja (2011), Abrupt warming of the Red Sea, Geophys. Res. Lett., 38, L14601, doi:10.1029/2011GL047984.

\section{Introduction}

[2] The Red Sea holds one of the most diverse marine ecosystems in the world, although fragile and vulnerable to oceanic warming [Cantin et al., 2010]. While global warming is evident across most of the tropical and subtropical seas, the Red Sea warming in particular appears to exceed the average marine tropical temperatures [Kleypas et al., 2008]. It is well documented that the consequences of the intense warming are apparent across the entire marine food web, i.e., from primary producers to toppredators, which can potentially lead to ecological breakdowns [Beaugrand, 2004; Richardson and Schoeman, 2004]. For instance, the increased warming has significantly slowed down the coral growth in the central Red Sea [Cantin et al., 2010], while in other cases it has resulted in the calcification cessation, coral bleaching (zooxanthellae loss) and mortality. In the past, the Earth's ecosystem has repeatedly gone through large climate changes [Alley et al., 2003]. However, it is the speed of change that controls the level of response of the ecological communities. In other

\footnotetext{
${ }^{1}$ Red Sea Research Centre, King Abdullah University for Science and Technology, Thuwal, Saudi Arabia.

${ }^{2}$ Hellenic Centre for Marine Research, Institute of Oceanography, Anavyssos, Greece.

Copyright 2011 by the American Geophysical Union. 0094-8276/11/2011GL047984
}

words, the ecological systems would have more chances to adapt in a slowly, rather than in a fast changing environment [Alley et al., 2003; deYoung et al., 2008]. Thus, particularly during the last decade there is a growing scientific interest in the detection and understanding of sudden changes or ecosystem regime shifts.

[3] The Advanced Very High Resolution Radiometer (AVHRR) Pathfinder data set has been characterized as the most extended time series of global sea surface temperature (SST) currently available [Nykjaer, 2009]. Although it was not initially intended to be used as a proxy in climate studies, it has been proved highly valuable for studying trends and anomalies over long time periods [Marullo et al., 2007; Nykjaer, 2009]. Despite the importance, there is no up-to-date detailed study assessing the Red Sea thermal regime through AVHRR. The goal of this study is to report the satellite derived spatiotemporal changes of the Red Sea temperatures, and assess whether the alterations observed during the last two decades originate from regional phenomena, or they are in part driven by global climate change trends.

\section{Methods}

\subsection{Data Sets}

[4] For this study, three different sources of temperature data were used, encompassing a period between 1985 and 2007 . Here we used the monthly SST means $\left(4 \times 4 \mathrm{~km}^{2}\right)$ of the AVHRR Pathfinder V5 data set, which is produced jointly by the National Oceanic and Atmospheric Administration (NOAA), and the National Aeronautics and Space Administration (NASA). To avoid the solar radiation bias that occurs during the day-time from surface heating, only the nighttime overpasses were employed [Nykjaer, 2009; Raitsos et al., 2006]. The accuracy of the satellite derived SSTs are documented in numerous studies [Nykjaer, 2009; Marullo et al., 2007, and references therein]. A recent detailed ground-truth validation study in the Mediterranean Sea reported that the AVHRR Pathfinder data related to an average error of less than $0.1 \mathrm{~K}$, while although satellites retrieve the temperature of the skin of the sea surface, the best fit was found at $4 \mathrm{~m}$ depth [Marullo et al., 2007]. The authors further reported that the error appeared to be weekly dependent on season, while it did not drift with time. Both aforementioned features make the Pathfinder SST a dependable data set for studying global and regional trends and anomalies [Marullo et al., 2007].

[5] Monthly means of the in situ air temperature data were obtained from the King Abdulaziz International Airport (KAIA), provided by the Presidency of Meteorology and Environment (PME) of Saudi Arabia. The Northern Hemisphere Temperatures (NHT) were acquired from the 

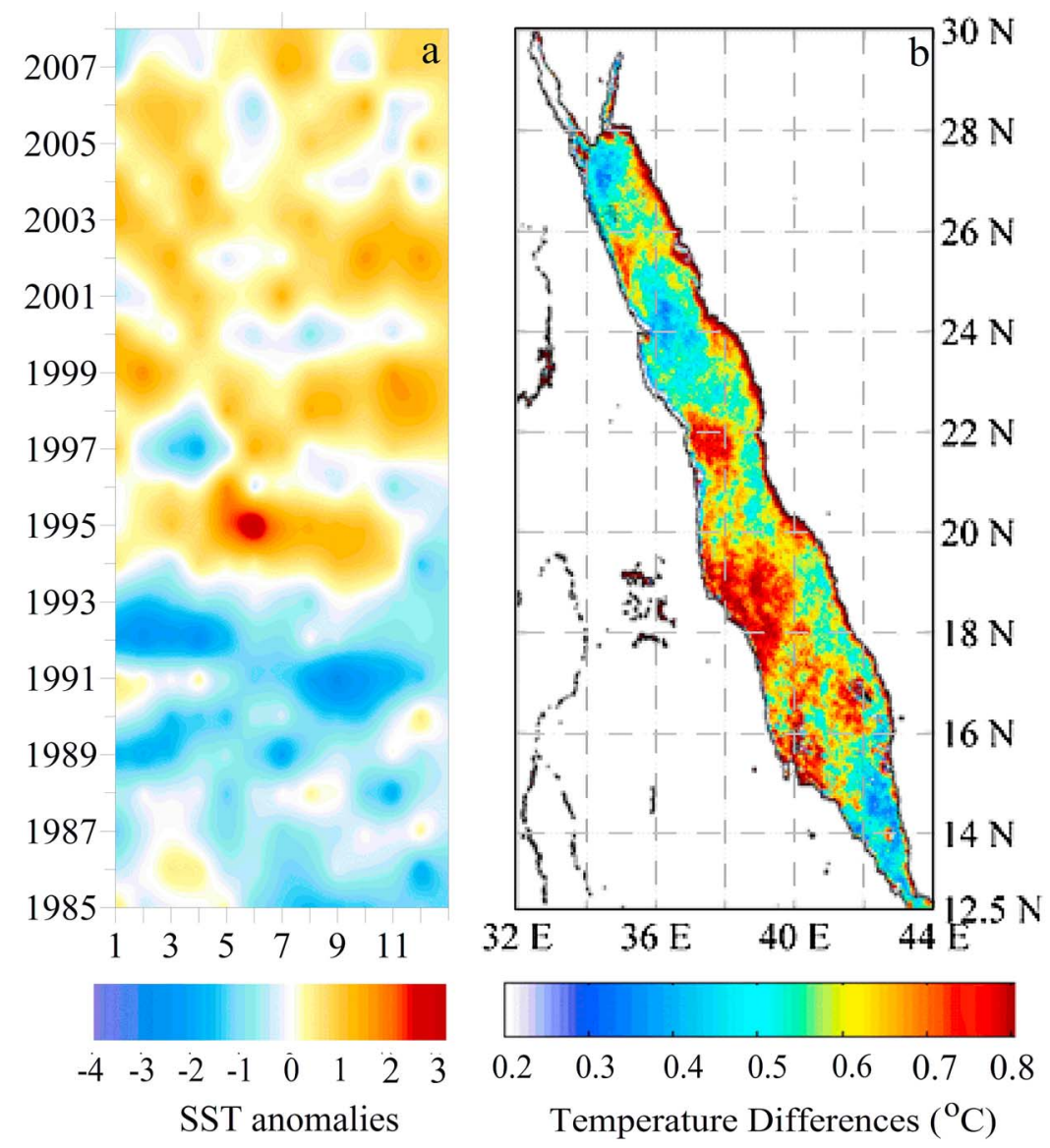

Figure 1. Temporal and spatial patterns of long-term satellite derived sea surface temperatures of the Red Sea for the period of 1985 to 2007. (a) Monthly time series of SST standardized anomalies (the blue colors represent a relatively colder period, while the red colors a warmer one), and (b) temperature differences $\left({ }^{\circ} \mathrm{C}\right)$ between the two decades, prior and post the abrupt SST shift (1985-1993 and 1994-2007 respectively). (Note that the scale represents only positive anomalies as negative ones were not apparent.)

Climatic Research Unit and Hadley Centre [Jones et al., 2008] and employed as anomalies relative to the 196190 reference period [Brohan et al., 2006]. The 1000hPa level monthly gridded geopotential height $(\mathrm{m})$ from the National Center for Environmental Prediction-Department Of Energy Reanalysis II (NCEP-DOE) was also used for the same period [Kalnay et al., 1996; Saha et al., 2006].

\subsection{Data Analysis}

[6] A regime shift index (RSI) combined with an automatic sequential algorithm [Rodionov, 2004] was employed to confirm the existence and statistical significance of abrupt changes in the data. The absolute value of RSI represents the magnitude of the shift(s) while its sign determines the change in direction of mean between regimes (see Rodionov [2004] for more information). The data were de-seasonalised (standardized anomalies) to reduce temporal autocorrelation. Pearson correlation and cross-correlation analysis were used to examine the relationships between the data sets. Here it has to be mentioned that the correlation coefficient and its significance level were reduced when performed on de-seasonalised data (compared to the original one). However, the seasonality within the monthly temperature time series is very strong and thus should be removed prior to the statistical analysis.

\section{Results and Discussion}

[7] The monthly SST anomaly time series revealed an abrupt warming that was initiated in 1994, while it was stabilized to the new warmer state few years later (Figure 1a). The warming trend is apparent in every month, implying that the change is not driven by seasonality. The most pronounced signals in this anomaly plot are the relatively colder winter of 1992 and the relatively warmer summer of 1995 and 1998. Using the NHT anomalies [Jones et al., 2008] it has been shown that the years 1995 and 1998 have ranked as the warmest years of the Northern Hemisphere, while the temperature shift at the end of the 1990s was the most intense change in the last 160 years [Raitsos et al., 2010]. While the satellite derived Red Sea SST data set revealed an intense and abrupt warming in the mid-90s, this may be part of a more widespread temperature shift seen in NHT at the beginning of the 80s [Brohan et al., 2006; Jones et al., 2008]. In addition, the features revealed from the SST differences prior (1985-1993) and after (1994-2007) the abrupt change, clearly underlines that the oceanic warming is evident over 


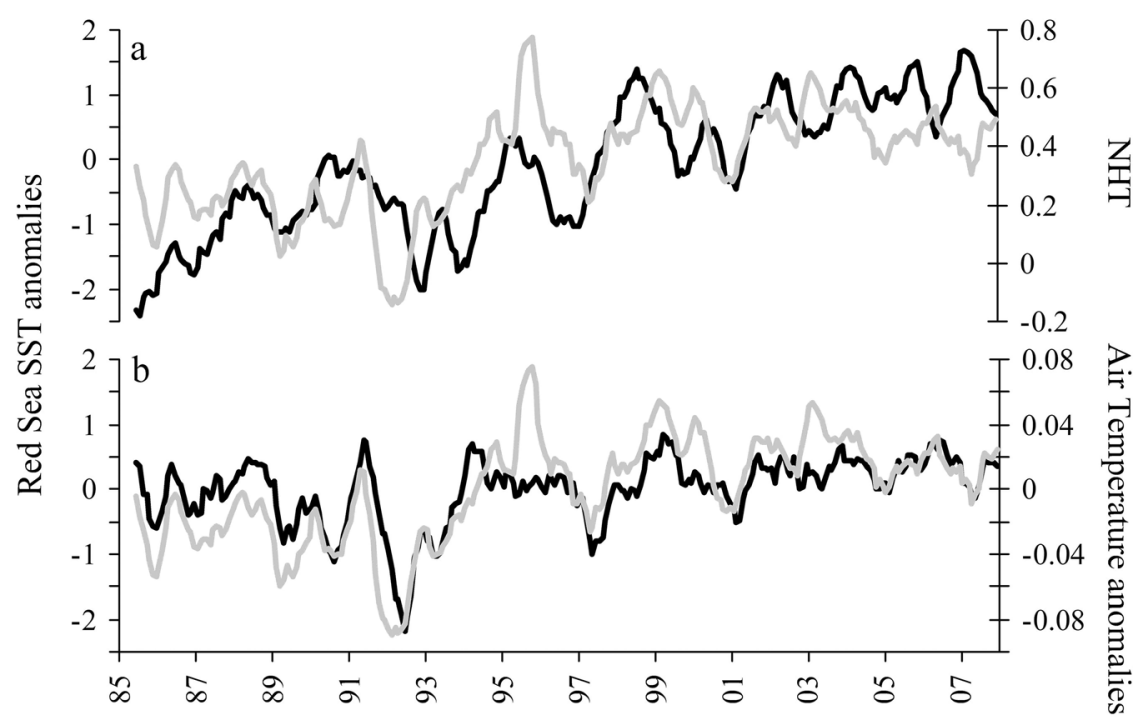

Figure 2. Moving averages (6 month) of the monthly de-seasonalised regional (marine and air) and Northern Hemisphere temperatures (1985-2007). (a) Monthly standardized anomalies of the Red Sea SST against NHT, (b) monthly standardized anomalies of the Red Sea SST versus in situ air temperature. The solid gray line stands for the SST, while the black one for the NHT and air temperature anomalies respectively.

the entire Red Sea (Figure 1b). The average difference between the two decades registers around $+0.62^{\circ} \mathrm{C}$ and in some areas exceeds the $1{ }^{\circ} \mathrm{C}$. It is the central part of the study area that portrays the highest deviations from the mean. This is in accordance with Cantin et al. [2010] reporting that the level of warming of the central Red Sea exceeds the observed mean tropical warming, an area that holds a very high diversity of corals.

[8] In order to examine whether the observed warming trends is a regional (Red Sea) characteristic or part of the current global warming trends, we used the NHT data set (Figure 2a). The results are presented as the 6 month moving averages to reduce the excess noise of monthly means. The NHT and the regional SST anomaly data sets parallel one another at a significant level, showing that the Red Sea temperature is influenced by the Northern Hemisphere trends (on a monthly $\mathrm{r}=0.44, \mathrm{p}=0.0001$, and annual scale $r=0.73, p=0.0001$ ). To further assess the mechanism behind the marine warming in the study area, monthly anomalies of the in situ air temperatures were plotted against the regional SST ones (Figure 2b). The marine temperature anomalies strongly parallel the in situ air temperature one $(\mathrm{r}=0.62, \mathrm{p}=0.001)$, indicating the climatic influence on the Red Sea warming. Strong correlation is also documented at an annual base $(r=0.78, p=0.0001)$. (Note that the correlation between the original monthly SST and air temperature, prior to seasonality removal, was $r=0.96, p<$ 0.00001 .) Cross-correlation analysis indicated that the best fit between SST and air temperatures occur at 1 month lag (for SST). In other words, the air temperature is found to be a key parameter that influences the Red Sea marine temperature, as it changes first and approximately 1 month later, the alteration is observed in the sea. The effect and the timing of the atmospheric forcing (air temperature) on the Red Sea shown herein, is consistent with findings from surrounding regions such as the Mediterranean Sea [Astraldi et al., 1995; Raitsos et al., 2010]. Finally, the NHT appeared to be significantly

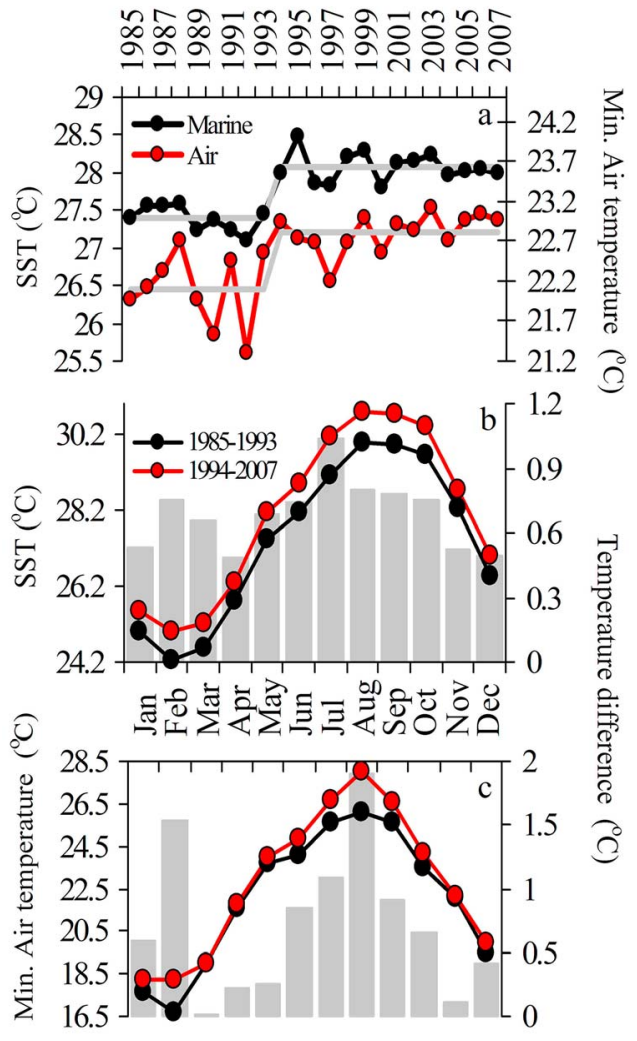

Figure 3. Red Sea annual time series of SST and minimum air temperature values since 1985 , along with their seasonal cycles. (a) Annual SST $\left({ }^{\circ} \mathrm{C}\right)$ against minimum air temperature values $\left({ }^{\circ} \mathrm{C}\right)$. The gray solid line represents the statistical significant regime shifts using Rodionov's automatic sequential algorithm. (b and c) Seasonal cycles of SST and minimum air temperature, along with the averaged difference $\left({ }^{\circ} \mathrm{C}\right)$ before and after the shift (1985-1993 and 1994-2007 respectively). 


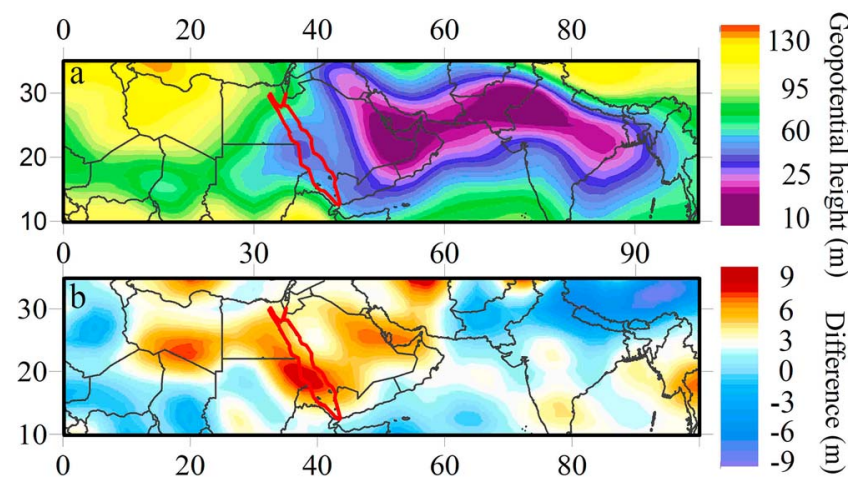

Figure 4. Numerical barometric pressure gridded at the $1000 \mathrm{hPa}$ level. (a) Composite of June-September surface geopotential height (m) from 1985 to 2007, and (b) difference prior and after the SST abrupt change (1985-1993 minus 1994-2007) of June-September surface geopotential height.

correlated with the in situ annual and monthly air temperature anomalies $(\mathrm{r}=0.56, \mathrm{p}=0.003$ and $\mathrm{r}=0.3, \mathrm{p}=0.001$, respectively) indicating that the anomaly signals and trends evident in regional air temperatures, which in sequence influence the Red Sea SST are related to the climate anomalies of the Northern Hemisphere.

[9] The analysis of the long-term (1985-2007) annual AVHRR SST revealed that not only the Red Sea is warming rapidly, but there is evidence of a temperature abrupt shift around 1994 (Figure 3a). It can be observed that before 1994 the annual SST mean remains below the overall mean, whereas after the abrupt shift the opposite pattern is observed. During the first decade (1985-1993) the annual SST mean was $27.4^{\circ} \mathrm{C}$, whereas during 1994-2007 the mean was $28.1^{\circ} \mathrm{C}\left(0.7^{\circ} \mathrm{C}\right.$ difference). This result is confirmed (using Hadley SST data), as it is reported that the Red Sea has changed by $0.74^{\circ} \mathrm{C}$ between 1982 and 2006 [Belkin, 2009]. The coldest registered year was 1992 after which a stepwise increase is evident (Figure 3a). Furthermore, the abrupt SST shift is related to a statistically significant change as the latter is assessed by the Rodionov's regime shift detection algorithm (year $=1994, R S I=1.02$, $p<0.0001)$. It is noteworthy that after the aforementioned stepwise increase, the SST has remained warmer without returning to its initial state. Additional analysis on in situ air temperature data revealed that the most extensive change was evident in terms of the minimum values. Figure $3 \mathrm{~b}$ shows that the lower minimum air temperatures have increased rapidly after $1994(R S I=0.46, p=0.002)$. Seasonal cycle analysis of both temperatures showed that the most prominent alterations occurred during the summer months (July and August), along with smaller changes during the winter months with a peak in February (Figures 3b and $3 \mathrm{c}$ ). Similar results are obtained if analysis is performed in maximum as well as in total values, however the changes are more pronounced in the minimum air temperature values. August and February are also the months that have changed the most in the eastern Mediterranean Sea [Raitsos et al., 2010]. The winter months and particularly February are very critical for primary production (for both the Red and Mediterranean Seas) as they are related to the phytoplankton blooms that are primarily formed due to the intense water column mixing. Increasing SSTs lead to more stratified conditions associated with reduced vertical mixing and thus nutrient availability in the upper oceanic layer. Such a situation can be detrimental to phytoplankton, which forms the base of the marine food chain [e.g., Raitsos et al., 2011; Richardson and Schoeman, 2004].

[10] The majority of the hitherto findings concern SST spatiotemporal trends, and how these are related to the broader changes seen in the Northern Hemisphere. To extend our working hypothesis, we investigate the involved proxy variable (i.e., SST) as a potential climate forcing regulator for the Red Sea area. Although not a direct recipient, the Red Sea bears few characteristics of the summer monsoonal regime (southwestern phase) dominant over the Arabian Sea and the Indian Ocean [Patzert, 1974]. These pertain to the northeastward expansion of the Arabian peninsula thermal low, which further interacts with the low level circulation known as the Somali Jet [Krishnamurti et al., 1976]. Figure 4a illustrates the summer (June to -September- monsoonal season) $1000 \mathrm{hPa}$ level geopotential height composite for the period 1985-2007, where the dominant low pressure system over the Arabian peninsula extends over the Red Sea. At the same time and despite the fact that precipitation over the area is very low (2-3 inches per year [Wang, 2006]) other feedback mechanisms may strongly implicate SST as a climate regulating factor. The herein documented SST warming trends are expected to favor additional evaporation, hence the deepening of the regional low pressures over the area is likely. In turn, Figure $4 \mathrm{~b}$ illustrates the respective numerical geopotential height difference prior to and after the herein documented SST abrupt change (1985-1993 period minus 1994-2007). It becomes evident that the period 19851993 is followed by an overall lowering of the pressure gradients during 1994-2007 (i.e., positive geopotential height differences, $1000 \mathrm{hPa}$, in meters) over the Red Sea, fact that supports the previous hypothesis. Additional implications arise from the aforementioned pressure re-distribution and these pertain to the zonal wind and cloudiness modulation over the study area. In fact, additional data analysis (not shown) depicts the intensification of the Somali Jet along with increased Outgoing Longwave Radiation values for the period 1994-2007.

\section{Conclusion}

[11] Regardless of its origin, natural and/or anthropogenic [Alley et al., 2003], it is widely accepted that oceanic warming is evident worldwide. The satellite retrieved SST revealed that the Red Sea is going through an intense warming that was initiated in the mid-90s, with evidence of an abrupt increase after 1994 (a result also shown from the air temperature data sets). Only during the last decade, the SST has increased by $0.7^{\circ} \mathrm{C}$. Spatiotemporal analysis showed that the thermal change is apparent in the whole Red Sea and in the entire year. Comparison with temperatures of the Northern Hemisphere suggested that the Red Sea warming is not a local phenomenon but a part of a widespread warming trend that is observed worldwide. In this view, the marine temperatures appeared to follow the air temperatures with 1 month delay, indicating the approximate time needed to see the changes in the sea. It is evident that the broader climate including atmospheric forcing and intensity of monsoons have been altered during the period of 
SST abrupt shift. This work brings a step closer toward reporting and understanding a temperature abrupt change seen in the Red Sea. However, the question as which factor has triggered this sudden alteration remains unanswered. Alley et al. [2003] mentioned that even a small and slow forcing can trigger an abrupt change. The description of the potential ocean temperature-lower atmosphere feedback would need further and detailed investigation.

[12] An abrupt climate change can potentially occur when the climate system is forced to overpass a particular threshold, while their economic and ecological impact could be significant [Alley et al., 2003]. It is predicted that the Red Sea temperature will increase as climate change continues [Cantin et al., 2010], a prediction that will further alter the regional ecosystem. The level of the Red Sea temperature change is one of the highest seeing, a result that is confirmed by other studies. Oceanic warming may have a direct or indirect impact on marine entities and ecosystems, thus, there is a need to assess further available past biological data (e.g., coral, fisheries, plankton) for potential responses to the new thermal state, and to closely monitor the relatively unexplored and fragile Red Sea ecosystem.

[13] Acknowledgments. We thank the Presidency of Meteorology and Environment (PME) of Saudi Arabia, for providing the air temperature data. We also thank Igor M. Belkin and one anonymous reviewer for their constructive comments. This research was supported by the King Abdullah University for Science and Technology (KAUST), Kingdom of Saudi Arabia.

[14] The Editor thanks two anonymous reviewers for their assistance in evaluating this paper.

\section{References}

Alley, R. B., et al. (2003), Abrupt climate change, Science, 299, 2005-2010, doi:10.1126/science.1081056.

Astraldi, M., C. N. Bianchi, G. P. Gasparini, and C. Morri (1995), Climatic fluctuations, current variability and marine species distribution: A case study in the Ligurian Sea (northwest Mediterranean), Oceanol. Acta, $18,139-149$.

Beaugrand, G. (2004), The North Sea regime shift: Evidence, causes, mechanisms and consequences, Prog. Oceanogr., 60, 245-262, doi:10.1016/j.pocean.2004.02.018.

Belkin, I. M. (2009), Rapid warming of large marine ecosystems, Prog. Oceanogr., 81, 207-213, doi:10.1016/j.pocean.2009.04.011.

Brohan, P., J. J. Kennedy, I. Harris, S. F. B. Tett, and P. D. Jones (2006), Uncertainty estimates in regional and global observed temperature changes: A new dataset from 1850, J. Geophys. Res., 111, D12106, doi:10.1029/2005JD006548.

Cantin, N. E., A. L. Cohen, K. B. Karnauskas, A. M. Tarrant, and D. C. McCorkle (2010), Ocean warming slows coral growth in the central Red Sea, Science, 329, doi:10.1126/science.1190182.
deYoung, B., M. Barange, G. Beaugrand, R. Harris, R. I. Perry, M. Scheffer, and F. Werner (2008), Regime shifts in marine ecosystems: Detection, prediction and management, Trends Ecol. Evol., 23, 402-409, doi:10.1016/j. tree.2008.03.008

Jones, P. D., D. E. Parker, T. J. Osborn, and K. R. Briffa (2008), Global and hemispheric temperature anomalies-Land and marine instrumental records, in Trends: A Compendium of Data on Global Change, Carbon Dioxide Inf. Anal. Cent., Oak Ridge Natl. Lab., U.S. Dep. of Energy, Oak Ridge, Tenn.

Kalnay, E., et al. (1996), The NCEP/NCAR 40-year re-analysis project, Bull. Am. Meteorol. Soc., 77, 437-471, doi:10.1175/1520-0477(1996) 077<0437:TNYRP $>2.0$.CO;2.

Kleypas, J. A., G. Danabasoglu, and J. M. Lough (2008), Potential role of the ocean thermostat in determining regional differences in coral reef bleaching events, Geophys. Res. Lett., 35, L03613, doi:10.1029/ 2007 GL032257.

Krishnamurti, T. N., J. Molinari, and H. L. Pan (1976), Numerical simulation of the Somali Jet, J. Atmos. Sci., 33, 2350-2362, doi:10.1175/15200469(1976)033<2350:NSOTSJ $>2.0 . C O ; 2$.

Marullo, S., B. B. Nardelli, M. Guarracino, and R. Santoleri (2007), Observing the Mediterranean Sea from space: 21 years of PathfinderAVHRR sea surface temperatures (1985 to 2005): Re-analysis and validation, Ocean Sci., 3, 299-310, doi:10.5194/os-3-299-2007.

Nykjaer, L. (2009), Mediterranean Sea surface warming 1985-2006, Clim. Res., 39, 11-17, doi:10.3354/cr00794.

Patzert, W. C. (1974), Wind-induced reversal in Red Sea circulation, Deep Sea Res. Oceanogr. Abstr., 21, 109-121, doi:10.1016/0011-7471(74) 90068-0.

Raitsos, D. E., S. J. Lavender, Y. Pradhan, T. Tyrrell, P. C. Reid, and M. Edwards (2006), Coccolithophore bloom size variation in response to the regional environment of the subarctic North Atlantic, Limnol. Oceanogr., 51, 2122-2130, doi:10.4319/lo.2006.51.5.2122.

Raitsos, D. E., G. Beaugrand, D. Georgopoulos, A. Zenetos, M. A. PancucciPapadopoulou, A. Theocharis, and E. Papathanassiou (2010), Global climate change amplifies the entry of tropical species into the eastern Mediterranean Sea, Limnol. Oceanogr., 55, 1478-1484, doi:10.4319/ lo.2010.55.4.1478.

Raitsos, D. E., S. J. Lavender, C. D. Maravelias, J. Haralabous, A. McQuatters-Gollop, M. Edwards, and P. C. Reid (2011), Macroscale factors affecting diatom abundance: A synergistic use of Continuous Plankton Recorder and satellite remote sensing data, Int. J. Remote Sens., 32, 2081-2094, doi:10.1080/01431161003645832.

Richardson, A. J., and D. S. Schoeman (2004), Climate impact on plankton ecosystems in the northeast Atlantic, Science, 305, 1609-1612, doi:10.1126/science. 1100958 .

Rodionov, S. N. (2004), A sequential algorithm for testing climate regime shifts, Geophys. Res. Lett., 31, L09204, doi:10.1029/2004GL019448.

Saha, S., et al. (2006), The NCEP Climate Forecast System, J. Clim., 19, 3483-3517, doi:10.1175/JCLI3812.1.

Wang, B. (2006), The Asian Monsoon, 844 pp., Springer, Chichester, U. K.

Y. Abualnaja, I. Hoteit, P. K. Prihartato, and D. E. Raitsos, Red Sea Research Centre, King Abdullah University for Science and Technology, Thuwal 23955-6900, Saudi Arabia. (yasser.abualnaja@kaust.edu.sa; ibrahim.hoteit@kaust.edu.sa; perdana.karim@kaust.edu.sa; dionysios. raitsos@kaust.edu.sa)

T. Chronis and G. Triantafyllou, Hellenic Centre for Marine Research, Institute of Oceanography, GR-190 13 Anavyssos, Greece. (themis@ath. hcmr.gr; gt@ath.hcmr.gr) 